\title{
UK guideline for the use of post-exposure prophylaxis for HIV following sexual exposure (2011)
}

\author{
P Benn MBChB FRCP*, M Fisher MBBS FRCP ${ }^{\dagger}$ and R Kulasegaram LRCP MRCS FRCP $\neq$, on behalf of the \\ BASHH§ PEPSE Guidelines Writing Group Clinical Effectiveness Group
}

${ }^{*}$ Camden Provider Services, Central and North West London NHS Foundation Trust, London; ${ }^{\dagger}$ Department of HIV/Genitourinary Medicine, Brighton and Sussex University Hospitals NHS Trust, Brighton; ‘Department of Genitourinary Medicine, Guy’s and St Thomas' NHS Foundation Trust, London; §British Association for Sexual Health and HIV, London, UK

Summary: We present the updated British Association for Sexual Health and HIV (BASHH) guidelines for post-exposure prophylaxis (PEPSE) to HIV. This document includes a review of the current data to support the use of PEPSE, considers how to calculate the risks of infection after a potential exposure, and provides recommendations on when PEPSE would and would not be considered. We review which agents to use for PEPSE including the potential for drug-drug interactions and make recommendations for monitoring individuals receiving PEPSE. Other areas included are the possible impact on sexual behaviour, cost-effectiveness and issues relating to service provision. Throughout the document, consideration is given to the place of PEPSE within the broader context of HIV prevention strategies and sexual health.

Keywords: post-exposure prophylaxis (PEP), sexual exposure, HIV, antiretroviral therapy, BASHH guidelines

\section{INTRODUCTION AND METHODOLOGY}

\section{Scope and purpose}

The main objective is to ensure the appropriate use of postexposure prophylaxis (PEP) following potential sexual

Correspondence to: P Benn

Email: paul.benn@nhs.net

BASHH PEPSE Guidelines Writing Group: Yusef Azad (representing NAT); Valerie Delpech, HIV and STI Department, Centre for Infections, HPA; Julie Fox, Consultant in GU Medicine, Guy's and St Thomas' NHS Foundation Trust; James Hardie, Health Adviser, Chelsea and Westminster Hospital (representing SSHA); David Hawkins, Consultant in GU Medicine, Chelsea and Westminster Hospital; Barbara Hedge, Consultant Clinical Psychologist (representing British Psychological Society); Keith Radcliffe, Consultant in GU Medicine, Whittall Street Clinic, Birmingham (representing Expert Advisory Group on AIDS); Claire Richardson, Pharmacist, Brighton and Sussex University Hospitals NHS Trust (representing HIVPA); Stephen Taylor, Consultant in Sexual Health and HIV Medicine, Birmingham Heartlands Hospital, Consultant Adviser to HM Armed Forces.

Membership of the CEG: Dr Keith Radcliffe (Chair) (BASHH), Dr David Daniels (BASHH NAG), Dr Mark FitzGerald (BASHH), Dr Margaret Kingston (BASHH), Dr Neil Lazaro (RCGP), Dr Gill McCarthy (BASHH) and Dr Ann Sullivan (BASHH). exposure (PEPSE) to HIV as a potential method of preventing HIV infection.

This guideline offers recommendations on the potential use of PEPSE, the circumstances in which it may be recommended, the treatment regimens that may be recommended and the appropriate use of subsequent diagnostic tests to measure individual outcomes. This guideline is intended to be complementary to the existing Department of Health (DH)/Expert Advisory Group on AIDS (EAGA) guidance on PEP. ${ }^{1}$

It is aimed primarily at clinicians and policy-makers in sexual health, sexual assault referral centres (SARCs), and primary and emergency care within the UK who should consider the development of appropriate local pathways. It is likely that this guideline will be used by voluntary sector agencies in providing information for individuals who may potentially be exposed to HIV during sexual activity.

\section{Stakeholder involvement}

The development of this guideline included a writing group with representatives from the British Association for Sexual Health and HIV (BASHH), British HIV Association (BHIVA), EAGA, Society of Sexual Health Advisers (SSHA), HIV Pharmacy Association (HIVPA), Health Protection Agency (HPA), the HIV and Sexual Health Group of the British Psychological Association, the Terrence Higgins Trust (THT) and the National AIDS Trust (NAT). Patients' perspectives were considered by involvement of THT, NAT and discussion at a stakeholder group organized by THT and the 
Community HIV and AIDS Prevention Strategy (CHAPS) conference.

\section{Rigour of development}

The guideline is based upon a comprehensive review of the literature pertaining to PEPSE. The recommendations are based upon a combination of biological plausibility, cohort studies, data from PEP in other settings and expert opinion. The recommendations are the result of a series of meetings of the writing committee and the input from the consultation process. Consensus opinion was reached in the event of disagreement. Prior to publication the final draft was placed on the BASHH website and copies were circulated to THT, BHIVA, and the DH for comment and peer review. After a period of three months any comments received were reviewed by the guideline authors, and acted upon appropriately, before final authorization by the clinical effectiveness group (CEG) was given and publication was undertaken. Feedback was also obtained from emergency medicine specialists and specialists managing victims of sexual assault.

A literature search using the terms 'post-exposure prophylaxis', 'HIV' and 'antiretroviral therapy' since the last guideline in 2005 was undertaken. This included review of databases (PubMed, Cochrane and Medline) and conference abstracts (Conference on Retroviruses and Opportunistic Infections, BHIVA, BASHH, International AIDS Society, International Society for Sexually Transmitted Diseases Research, International Union against Sexually Transmitted Infections (IUSTI) and the Health Technology Assessment programme). The following journals (AIDS, HIV Medicine, International Journal of STD \& AIDS, Journal of Acquired Immune Deficiency Syndrome, Sexually Transmitted Diseases and Sexually Transmitted Infections) were hand searched for relevant articles.

\section{BACKGROUND}

Pathogenesis studies indicate that there may be a window of opportunity to abort HIV infection by inhibiting viral replication following an exposure. Once HIV crosses a mucosal barrier $^{2}$ it may take up to $48-72$ hours before HIV can be detected within regional lymph nodes and up to five days before HIV can be detected in blood. ${ }^{3,4}$ Initiation of antiretroviral therapy (ART) has been shown to reduce dissemination and replication of virus in all tissues if initiated early after inoculation in an animal model. ${ }^{5}$

\section{RISKS OF HIV TRANSMISSION}

The risk of an individual acquiring HIV following an exposure is dependent upon the risk that the source is HIVpositive where unknown (Table 1) and the risk of infection following a specific exposure from an HIV-positive individual (Table 2):

Risk of HIV transmission $=$ risk that source is HIV-positive

$$
\times \text { risk of exposure* }
$$

$(*$ including co-factors such as sexually transmitted infections [STIs], high HIV viral load and bleeding).
Table 1 shows the estimated HIV prevalence (including both diagnosed and undiagnosed infection) in adults aged over 15 years in the UK in 2009.

The probability of HIV transmission depends upon the exposure characteristics, the infectivity of the source and host

Table 1 Risk that the source is HIV-positive

\begin{tabular}{|c|c|c|}
\hline \multirow[b]{2}{*}{ Population group } & \multicolumn{2}{|c|}{ HIV prevalence (\%) } \\
\hline & Men & Women \\
\hline \multicolumn{3}{|c|}{ Men who have sex with men (MSM)* } \\
\hline UK & 4.4 & - \\
\hline London & 8.1 & - \\
\hline Elsewhere in the UK & $3.1^{\dagger}$ & - \\
\hline \multicolumn{3}{|c|}{ Heterosexuals (region of birth) ${ }^{\ddagger}$} \\
\hline Sub-Saharan Africa & 3.1 & 6.2 \\
\hline Elsewhere & 0.05 & 0.03 \\
\hline \multicolumn{3}{|c|}{ Injecting drug users ${ }^{\S}$ (IDU; ever injected) } \\
\hline London & 0.9 & \\
\hline Elsewhere in the UK & 0.4 & \\
\hline
\end{tabular}

${ }^{*}$ An estimate of the size of the MSM population was $3.4 \%$ within the UK, $7.0 \%$ within London and $2.8 \%$ in areas outside of London (Presanis, 2010). This was applied to the male population aged over 15 years (derived from ONS) to provide the population denominator. The numerator was derived from MPES (ibid) adjusted with SOPHID data to take account of MSM living with HIV aged over 59 years

${ }^{T}$ The prevalence of HIV among MSM varies across the UK and is higher in metropolitan areas with large MSM populations, including Brighton and Manchester, where community-based prevalence studies have suggested rates of $13.7 \%$ and $8.6 \%$, respectively 6,7

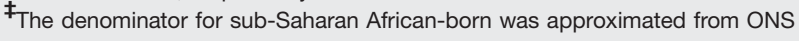
('black or black British, black African') aged over 15 years. Heterosexuals 'born elsewhere' were estimated from ONS (total population minus the black African population) aged over 15 years. The numerator was derived from MPES (Presanis, 2010) adjusted with SOPHID data to take account of heterosexuals living with HIV aged over 59 years. These data are for England and Wales only

${ }^{\$}$ Current and former injectors are included. An estimate of the size of the IDU population was derived from Harris (2011). This was applied to the adult population (derived from ONS) to provide the population denominator. The numerator was taken from MPES (Presanis, 2010). This was adjusted with SOPHID data to account for IDUs living with HIV aged over 59 years

Contemporaneous prevalence estimates can be obtained at http://www.hpa.org. $\mathrm{uk} /$ infections/topics_az/hiv and AIDS. Prevalence rates for exposures outside of the UK or for individuals recently moved to the UK can be obtained at http://www. unaids.org

NB: the prevalence of individuals who have moved to the UK tends to be below that in their original country

Table 2 Risk of HIV transmission following an exposure from a known HIV-positive individual

\begin{tabular}{ll}
\hline Type of exposure & $\begin{array}{l}\text { Estimated median (range) risk of } \\
\text { HIV transmission per exposure (\%) }\end{array}$ \\
\hline Receptive anal intercourse & $1.11(0.042-3.0 \%)^{9-15}$ \\
Insertive anal intercourse & $0.06(0.06-0.065 \%)^{9,11,12,16}$ \\
Receptive vaginal intercourse & $0.1(0.004-0.32 \%)^{9,14,17-26}$ \\
Insertive vaginal intercourse & $0.082(0.011-0.38 \%)^{13,14,17-20,23,27,28}$ \\
Receptive oral sex (giving fellatio) & $0.02(0-0.04 \%)^{12,29}$ \\
Insertive oral sex (receiving fellatio) & $0^{11,29}$ \\
Blood transfusion (one unit) & $(90-100 \%)^{30}$ \\
Needlestick injury & $0.3(95 \% \mathrm{Cl} 0.2-0.5 \%)^{31-33}$ \\
Sharing injecting equipment & $0.67^{34}$ \\
Mucous membrane exposure & $0.63(95 \% \mathrm{Cl} 0.018-3.47 \%)^{* 35}$
\end{tabular}

NB: All sexually related risk probabilities are for unprotected sexual exposure; it is assumed similar risks will exist where condom failure has occurred

*The writing committee has concern regarding the risk estimate following mucous membrane exposures, which is derived from a single study including only small numbers of health-care workers exposed to HIV following mucous membrane exposures. This is likely to significantly overestimate the risk 
Table 3 Calculating the estimated risk of HIV transmission according to the likelihood that the source is HIV-positive and the risk following a single exposure with someone known to be HIV-positive

\begin{tabular}{|c|c|c|c|c|c|}
\hline \multirow{3}{*}{$\begin{array}{l}\text { Type of exposure } \\
\text { Unprotected receptive anal intercourse }\end{array}$} & \multirow{3}{*}{$\begin{array}{l}\text { Population group } \\
\text { MSM in London } \\
\text { MSM elsewhere in the UK }\end{array}$} & \multicolumn{2}{|c|}{$\begin{array}{l}\text { Risk of HIV transmission } \\
\text { (source of unknown HIV status)* }^{*}\end{array}$} & \multicolumn{2}{|c|}{$\begin{array}{l}\text { Risk of HIV transmission } \\
\text { (source is HIV-positive) }\end{array}$} \\
\hline & & $0.081 \times 1.11 \%=0.09 \%$ & $1 / 1,112$ & $1 \times 1.11 \%=1.11 \%$ & $1 / 90$ \\
\hline & & $0.031 \times 1.11 \%=0.034 \%$ & $1 / 2,906^{\dagger}$ & & \\
\hline \multirow[t]{2}{*}{ Unprotected insertive anal intercourse } & MSM in London & $0.081 \times 0.06 \%=0.0049 \%$ & $1 / 20,408$ & $1 \times 0.06 \%=0.06 \%$ & $1 / 1667$ \\
\hline & MSM elsewhere in the UK & $0.031 \times 0.06 \%=0.0019 \%$ & $1 / 52,632^{\dagger}$ & & \\
\hline \multirow{2}{*}{$\begin{array}{l}\text { Unprotected receptive oral intercourse } \\
\text { (giving fellatio) }\end{array}$} & MSM in London & $0.081 \times 0.02 \%=0.0016 \%$ & $1 / 62,500$ & $1 \times 0.02 \%=0.02 \%$ & $1 / 5000$ \\
\hline & MSM elsewhere in the UK & $0.031 \times 0.02 \%=0.0006 \%$ & $1 / 166,667$ & & \\
\hline \multirow[t]{2}{*}{ Unprotected receptive vaginal intercourse } & $\begin{array}{l}\text { Heterosexual man born in sub-Saharan } \\
\text { Africa }\end{array}$ & $0.031 \times 0.1 \%=0.0031 \%$ & $1 / 32,258$ & $1 \times 0.1 \%=0.1 \%$ & $1 / 1000$ \\
\hline & Heterosexual man born in UK & $0.005 \times 0.1 \%=0.0005 \%$ & $1 / 200,000$ & & \\
\hline \multirow[t]{2}{*}{ Unprotected insertive vaginal intercourse } & $\begin{array}{l}\text { Heterosexual woman born in } \\
\text { sub-Saharan Africa }\end{array}$ & $0.062 \times 0.082 \%=0.0051 \%$ & $1 / 19,608$ & $1 \times 0.082 \%=0.082 \%$ & $1 / 1220$ \\
\hline & Heterosexual woman born in UK & $0.003 \times 0.082 \%=0.00025 \%$ & $1 / 400,000$ & & \\
\hline \multirow[t]{2}{*}{ Sharing injecting equipment } & IDU in London & $0.009 \times 0.67 \%=0.006 \%$ & $1 / 16,667$ & $1 \times 0.67 \%=0.67 \%$ & $1 / 149$ \\
\hline & IDU elsewhere in the UK & $0.004 \times 0.67 \%=0.0027 \%$ & $1 / 37,037$ & & \\
\hline \multicolumn{6}{|c|}{$\mathrm{MSM}=$ men who have sex with men; IDU = intravenous drug user } \\
\hline \multirow{3}{*}{\multicolumn{6}{|c|}{$\begin{array}{l}\text { *Risk is calculated using data from Tables } 1 \text { and } 2 \text { according to the formula: risk of HIV transmission }=\text { risk that source is HIV-positive } \times \text { risk of exposure } \\
\text { In some circumstances the risk of HIV transmission is clearly greater than that following occupational exposure in which PEP is routinely considered: } 1 / 300 \text { for a known } \\
\text { HIV-positive 'source'1 }\end{array}$}} \\
\hline & & & & & \\
\hline & & & & & \\
\hline \multicolumn{6}{|c|}{$\begin{array}{l}\text { There may be special circumstances that may increase or decrease the risk of an exposure, including the presence of concurrent sexually transmitted infections, circumcision or } \\
\text { acute HIV seroconversion }\end{array}$} \\
\hline${ }^{\dagger}$ The prevalence of HIV among MSM across & he UK varies and is high in some regions, in & Cluding Rriabton and Manchecter & & & \\
\hline
\end{tabular}

susceptibility. The following factors may increase the risk of HIV transmission:

- A high plasma HIV viral load in the source (this may be particularly relevant during primary HIV infection). Although low or undetectable plasma viral loads reduce the risk, transmission may still be possible; ${ }^{17,25,31,35}$

- Viral loads in the genital tract normally correlate with plasma viral loads. In general, the genital tract viral load is also undetectable when the plasma viral load is undetectable. When this is not the case the viral load in the genital tract is usually low; ${ }^{35-48}$

- Breaches in the mucosal barrier such as mouth or genital ulcer disease and trauma following sexual assault or first intercourse may increase the risk of HIV acquisition. ${ }^{49,50}$ Menstruation or other bleeding may also facilitate transmission;

- STIs enhance HIV transmission in epidemiological studies and increase HIV shedding from the genital tract. (This may not be the case in individuals receiving effective ART $) i^{50-58}$

- The risk of HIV transmission is likely to be greater if ejaculation occurs. Among a community cohort of men who have sex with men (MSM) the risk of HIV acquisition per episode of unprotected receptive anal intercourse with and without ejaculation was estimated to be $1.43 \%$ (95\% confidence interval [CI] $0.48-2.85)$ and $0.65 \%$ (95\% CI $0.15-$ 1.53), respectively; ${ }^{59}$

- Non-circumcision may increase the risk of HIV acquisition. ${ }^{60}$ Circumcision has been shown to significantly reduce HIV acquisition among heterosexual men in high prevalence countries. $^{61-63}$ A meta-analysis of observational studies among MSM suggests circumcision has little impact upon HIV acquisition. ${ }^{64}$ Among a community cohort of MSM the risk of HIV acquisition per episode of unprotected insertive anal intercourse in men who have been circumcised and have not been circumcised was estimated to be $0.11 \%$ (95\% CI $0.02-0.24$ ) and $0.62 \%$ (95\% CI $0.07-1.68)$, respectively. $^{59}$

\section{CALCULATING THE RISK OF HIV TRANSMISSION}

Table 3 provides examples of estimates of an individual's risk of HIV transmission if the source is known to be HIV-positive or of unknown status according to type of exposure. Co-factors such as STIs, viral load and bleeding may affect the risk estimate. Knowledge of local HIV prevalence rates will clearly assist in calculating the risk of transmission and therefore developing local policy. Where individuals have had multiple exposures within 72 hours of presentation the cumulative risk should be considered.

\section{DATA SUPPORTING THE USE OF PEP AGAINST HIV}

\section{Animal studies}

Numerous animal models have been reported. However, they are not standardized and use different retroviruses, size of inocula and modes of administration. Differences in drug metabolism between human and animals are another limitation to consider when interpreting these studies.

A phase I/II clinical trial using PMPA (tenofovir) administered subcutaneously for PEP demonstrated that simian immunodeficiency virus infection was prevented following an intravenous inoculation in $100 \%$ of macaques if administered within 24 hours and continued for 28 days. As either the time to initiation of PEP was increased or the duration of PEP was 
reduced then the number of macaques protected declined. ${ }^{65} \mathrm{~A}$ further study using PMPA (tenofovir) administered subcutaneously for PEP in macaques showed 100\% protection against HIV-2 following an intravaginal challenge if administered within 36 hours of the exposure. ${ }^{66}$

However, not all animal studies demonstrate a protective effect of PEP. A study using a combination of zidovudine, lamivudine and indinavir administered orally offered no protection following intravenous inoculation, even if initiated within four hours of the innoculation. ${ }^{67}$ The absence of protection observed in this study may result from the mode of administration or size of the inoculum used.

Animal studies conducted more recently have demonstrated that intermittent pre-exposure prophylaxis (PrEP) and PEP using oral Truvada (tenofovir and emtricitabine) prevented acquisition of infection in some/all macaques exposed rectally for 14 weeks using low-dose (physiological) inocula. The level of protection varied according to the timing of doses, with the highest level of protection being offered when the first dose was administered between 22 hours and seven days prior to the exposure and a second dose two hours after the exposure. This study demonstrated that a dose administered post-exposure was required to prevent infection, with all animals given only a pre-exposure dose becoming infected. ${ }^{68}$ No protection was observed if the first dose was delayed until 24 hours after the exposure. ${ }^{68}$

These animal studies suggest that PEP is potentially effective and that time to initiation and duration are important.

\section{Human studies}

\section{Occupational exposure to HIV}

Prospective randomized controlled trials (RCTs) to determine the efficacy of PEP are not feasible, due to (a) the ethical problems of withholding a potentially efficacious treatment, and (b) the difficulty in recruiting a high number of participants that would be required for such a study. However a retrospective case-controlled study among health-care workers occupationally exposed to HIV infection demonstrated that a 28-day course of zidovudine was protective, odds ratio (OR) 0.19 (95\% CI $0.06-0.52 \%) .{ }^{31}$ This study has some limitations, including a small number of cases $(n=33)$ and cases and controls $(n$ $=665$ ) were derived from different countries and details of exposure characteristics of cases were collected retrospectively. Adjustments were needed to take into account the fact that the likelihood of receiving zidovudine was related to the likelihood of transmission (size of inoculum, source patient has AIDS, etc).

These studies suggest that PEP may be protective. However there are at least 24 instances where PEP (in most cases zidovudine monotherapy) has failed to prevent HIV infection following occupational exposure. ${ }^{69}$

In addition, there is no human evidence to support any additional benefit of the use of combination ART for PEP. However 'absence of evidence' does not equal 'evidence of absence' and it is argued that the efficacy of triple therapy in treatment regimens is much more effective at lowering viral load than monotherapy, and that triple therapy should be given (IV, grade C).

\section{Vertical transmission}

Several studies to reduce vertical transmission may also suggest that PEP may be protective. In a subset of women participating in the AIDS Clinical Trials Group (ACTG) 076 study who did not receive zidovudine prior to delivery, where the neonate was given a six-week course of zidovudine, initiated within 48 hours of delivery, a protective effect was observed..$^{70,71}$

\section{Data on PEP after sexual exposure}

In a recent systematic review no prospective RCTs to determine the efficacy of PEPSE were identified. The review concluded that it was not possible to determine the effectiveness due to the lack of evidence, but that it may be costeffective in certain circumstances. ${ }^{72}$ Two observational PEPSE studies undertaken in Brazil: one among MSM and another among women following sexual assault demonstrated that fewer HIV seroconversions occurred among individuals taking PEPSE compared with those who did not. However, both studies were not powered to detect a difference in HIV incidence. $^{73}$

\section{Factors influencing the efficacy of PEP}

PEP is not $100 \%$ effective and individuals have acquired HIV despite commencing PEP following both occupational and sexual exposures. Delayed initiation of PEP, presence of resistant virus in the source, different penetration of drugs into tissue compartments, poor/non-adherence and further highrisk sexual exposures may explain some transmissions. ${ }^{65}$ These factors are discussed in more detail below.

\section{Delays in initiating PEP}

Delays in commencing PEP may adversely its affect its efficacy. ${ }^{31,65}$ PEP may be less or ineffective if initiated after 72 hours of the exposure and is not recommended (IV, grade C). Occupational guidelines recommend that PEP be commenced as soon as possible after the exposure, ideally within one hour (IV, grade C). Trust policies and the availability of starter packs may improve the time to initiation of PEP. In comparison, the time to initiating PEPSE is often longer ${ }^{74,75}$ but may be reduced by improving awareness among both patients and health-care professionals.

\section{Drug resistance in the source}

Reports suggest that the prevalence of antiretroviral resistance among those with primary HIV infection and those chronically infected with HIV has levelled at $8 \%$ in the UK and Europe; ${ }^{76,77}$ however this may not be the case in other countries, including the USA. ${ }^{78}$ Transmission of virus that is resistant to one or more of the agents used for PEP may reduce its efficacy. If drug resistance is suspected in the source the PEP regimen should be tailored accordingly (III, grade B). Resistance testing of the source may be considered.

\section{Drug penetration into tissue compartments}

Compartmentalization of HIV, in particular within the genital tract, may result in differential virus evolution or evolution of resistance, which may have implications for transmission. Studies suggest that virus with replicative capacity can be detected within different tissue compartments despite optimal viral suppression within the blood. ${ }^{79,80}$ Pharmacological studies also suggest that individual antiretroviral agents penetrate these compartments, including the genital tract, to 
varying degrees. ${ }^{81-85}$ Further information regarding the penetration of different antiretroviral agents is discussed later (see considerations for which drugs to use for PEP).

\section{Poor/non-adherence}

Adherence and completion rates to four weeks of PEP among health-care workers and individuals exposed nonoccupationally have been historically poor, which may impact upon its efficacy. ${ }^{86-88}$ It is unclear whether issues other than pill burden and side-effects, such as psychological distress or the re-evaluation of risk over time, influence adherence and completion rates. A study among 401 individuals receiving dual nucleoside therapy for PEP following non-occupational exposure reported completion rates of $78 \%$. Individuals received three adherence sessions and five risk reduction sessions, which may account for the improved completion rates. $^{87}$ In those chronically infected with HIV, adherence to combination ART is directed related to virological outcome. Poor adherence to PEP regimens theoretically may result in the acquisition of a drug-resistant virus should the individual become HIV infected. This has been suggested as a risk for subsequent seroconversion in a retrospective analysis of PEPSE failures. ${ }^{89}$ It is likely that adherence and treatment completion will be greater with better-tolerated PEP regimens.

\section{Possible risks of PEP}

The frequency, severity, duration and reversibility of sideeffects and potential for as yet unknown long-term complications must be compared with the potential benefit of PEP. The use of nevirapine for PEP has been shown to be associated with significant toxicity, which highlights that in some circumstances the risk of PEP itself may outweigh the potential for benefit $^{90,91}$ (III, grade B). Further discussion regarding the suitability of different agents for inclusion within PEP regimens are given below (see recommendations for which drug regimen to use).

\section{POTENTIAL BEHAVIOURAL/ PSYCHOLOGICAL IMPLICATIONS OF OFFERING PEPSE}

There are concerns that the availability of PEPSE will reduce commitment to primary prevention strategies and consequently result in more frequent high-risk behaviour. ${ }^{92}$

Some studies provide evidence that the availability of PEPSE increases risk behaviour. While most MSM in the USA may not intend to use PEPSE, younger, less-educated MSM may report greater intentions to use PEPSE, especially if they had engaged in high-risk sexual behaviour and had a history of injecting drug use. ${ }^{93}$

However, other studies provide evidence that there may be no increase in risk behaviour. ${ }^{94}$ The awareness of PEP was reported to have no effect on the condom use in serodiscordant couples participating in a cross-sectional survey, ${ }^{95}$ while self-reported risk behaviour significantly decreased following PEPSE in a Brazilian cohort of $\mathrm{MSM}^{72}$ and in two San Francisco clinics that provided PEPSE to MSM. ${ }^{96}$

A study undertaken in a community cohort of HIV-negative MSM in Australia demonstrated that the use of PEP was not associated with a reduction in risk behaviour.
High-risk behaviours were frequently reported; however, PEP was only sought for a minority of episodes despite high levels of PEP awareness. The reasons for this are unclear. Although HIV incidence was higher among MSM receiving $\mathrm{PEP}$, this was no longer significant after controlling for sexual behaviour. ${ }^{97}$

Some authors have argued that health-related interventions such as PEPSE may help capitalize on 'close calls' to motivate and sustain risk reduction in individuals who have engaged in risk behaviour. ${ }^{98,99}$

\section{Acute anxiety}

While it is recognized that individuals may present in a state of acute anxiety following possible exposure to HIV, the decision to administer PEP should be based upon the risk of HIV acquisition and the potential adverse effects of ART. Individuals should be reassured that in general the risk of HIV acquisition is low. Referral for psychological support for individuals reporting anxiety in particular around the risk of transmission may help to alleviate such anxiety (IV, grade C).

\section{RECOMMENDATIONS FOR PRESCRIBING PEPSE}

The writing committee feels it is crucial to consider PEPSE as only one strategy for preventing HIV infection and, as such, should be considered as a last measure where conventional, and proven, methods of HIV prevention have failed (IIb, grade $\mathrm{B})$.

A risk versus benefit analysis should be undertaken for every individual presenting following an exposure and the decision to initiate PEP made on a case-by-case basis. This should consider both the risk of transmission according to exposure (as in Table 2) and the risk of the source being HIV-positive (as in Table 1) as well as the viral load in the source if known (IV, grade C). The situations when PEPSE should be considered are shown in Table 4 . The writing committee recommends that PEPSE is indicated when the estimated transmission risk is 1 in 1000 or greater (IV, grade C).

Unprotected receptive anal intercourse with someone of unknown HIV status from a high HIV prevalent group or area is included in the 'recommend' category, even though the risk may be less than 1 in 1000, given that this the major route of HIV transmission within the UK. Similarly unprotected insertive anal intercourse with someone known to be HIV-positive with a detectable viral load is included in the 'recommend' category, despite having a slightly lower risk estimate, for simplicity and in light of the recent data from Jin et al. ${ }^{59}$

Where the estimated transmission risk is between 1 in 1000 and 1 in 10,000 PEP may be considered. The writing committee feels that when the exposure is classified as 'consider', PEPSE should only be prescribed if there are additional factors that may increase the likelihood of transmission, i.e. following sexual assault, in the presence of an STI (i.e. where the source is known to have an STI or the exposed individual has symptoms or signs suggesting an STI) or where the source is suspected to have acute HIV infection. Awareness of the local seroprevalence of HIV in the potential source clearly should be factored into local protocols. In the absence of additional 
Table 4 Situations when post-exposure prophylaxis (PEP) is considered (IV, grade C)

\begin{tabular}{|c|c|c|c|c|}
\hline & \multicolumn{4}{|c|}{ Source HIV status } \\
\hline & \multicolumn{2}{|c|}{ HIV-positive } & \multirow{2}{*}{$\begin{array}{l}\text { Unknown from high } \\
\text { prevalence group/area* }\end{array}$} & \multirow{2}{*}{$\begin{array}{l}\text { Unknown from low } \\
\text { prevalence group/area }\end{array}$} \\
\hline & Viral load detectable & Viral load undetectable & & \\
\hline Receptive anal sex & Recommend & Recommend & Recommend & Not recommended \\
\hline Insertive anal sex & Recommend & Not recommended & Consider ${ }^{\dagger}$ & Not recommended \\
\hline Receptive vaginal sex & Recommend & Not recommended & Consider $^{\dagger}$ & Not recommended \\
\hline Insertive vaginal sex & Recommend & Not recommended & Consider $^{\dagger}$ & Not recommended \\
\hline Fellatio with ejaculation $^{\ddagger}$ & Consider & Not recommended & Not recommended & Not recommended \\
\hline Fellatio without ejaculation ${ }^{\ddagger}$ & Not recommended & Not recommended & Not recommended & Not recommended \\
\hline Splash of semen into eye & Consider & Not recommended & Not recommended & Not recommended \\
\hline Cunnilingus & Not recommended & Not recommended & Not recommended & Not recommended \\
\hline Sharing of injecting equipment & Recommended & Not recommended & Consider & Not recommended \\
\hline Human bite $\S$ & Not recommended & Not recommended & Not recommended & Not recommended \\
\hline $\begin{array}{l}\text { Needlestick from a discarded needle } \\
\text { in the community }\end{array}$ & & & Not recommended & Not recommended \\
\hline \multicolumn{5}{|c|}{$\begin{array}{l}{ }^{*} \text { High prevalence groups within this recommendation are those where there is a significant likelihood of the sou } \\
\text { likely to be men who have sex with men and individuals who have immigrated to the UK from areas of high } \\
{ }^{\dagger} \text { More detailed knowledge of local prevalence of HIV within communities may change these recommendations } \\
\text { prevalence } \\
{ }^{+} \text {PEP is not recommended for individuals receiving fellatio i.e. inserting their penis into another's oral cavity } \\
{ }_{\text {A bite is assumed to constitute breakage of the skin with passage of blood }}\end{array}$} \\
\hline
\end{tabular}

factors PEPSE should not be prescribed when the exposure is classified as 'consider'.

Where the estimated transmission risk is below 1 in 10,000, $\mathrm{PEP}$ is not recommended (IV, grade C). These thresholds are similar to those used in the Australian non-occupational PEP guidelines $^{100}$ and broadly correlate to circumstances where PEP is likely to be cost-effective (see cost-effectiveness of PEP following non-occupational exposures).

Consideration should be given to the possibility of the presenting individual having already been infected with HIV, and the ability to adhere to and tolerate the proposed antiretroviral drug regimen. The potential exposure to other STIs and appropriate management of these needs to be considered alongside consideration of provision of PEPSE. The wishes of the individual should be considered at all times (IV, grade C).

\section{SITUATIONS IN WHICH PEPSE WOULD BE CONSIDERED}

The use of PEPSE following potential sexual exposure to HIV is only recommended where the individual presents within 72 hours of exposure (IIb, grade B). Within that time frame, it is recommended that PEPSE (if given) should be administered as early as possible. All recommendations are for either unprotected sexual exposure or where condom failure has occurred. Recommendations regarding fellatio are where the partner giving fellatio is presenting for PEPSE.

\section{Source individual is known to be HIV-positive}

In this scenario attempts should be made at the earliest possible stage to determine the viral load, resistance profile and treatment history in the source individual. Where the viral load is undetectable it is assumed that the risk of transmission will be significantly reduced. The majority of supporting evidence is derived from heterosexual discordant couples although there are some data among MSM. ${ }^{101}$ There are anecdotal reports of transmission where the source is thought to have an undetectable plasma viral load. ${ }^{102}$ In light of this evidence we have therefore downgraded the recommendation from the previous guidelines for PEP where the source is known to be HIV-positive with an undetectable plasma viral load to 'not recommend' with the exception of unprotected receptive anal intercourse, which in the absence of further data remains 'recommended' (see Table 4) (IV, grade C).

\section{Source individual is of unknown status}

Attempts should be made, where possible, to establish the HIV status of the source individual (according to appropriate guidance on HIV testing and consent) as early as possible (III, grade B). There is growing evidence to suggest that significant numbers of PEP cases can be averted through assertive HIV testing of the source individual. ${ }^{103}$ It is therefore recommended that strong efforts be made to encourage the individual to notify their partner where possible, and for the clinic to arrange urgent HIV testing of that partner, with appropriate guidance on HIV testing and consent, as early as possible.

If the source is from a group or area of high HIV prevalence then PEP is recommended following receptive anal sex only. Where the source is not from a group or area of high HIV prevalence then PEP is not recommended (see Table 4) (IV, grade C).

\section{Other circumstances}

\section{Sexual assault}

It is believed that transmission of HIV is likely to be increased following aggravated sexual intercourse (anal or vaginal), such as that experienced during sexual assault. Clinicians may therefore consider recommending PEPSE more readily in such situations. While the routine recommendation of PEPSE is likely to be appropriate in high prevalence situations, ${ }^{104}$ it is likely that the strength of recommendation and subsequent uptake will be lower in UK settings unless the 'assailant' is perceived to be from a high prevalence group (IV, grade C). 


\section{Needlestick injuries in the community}

It is not uncommon for individuals to request PEP following a needlestick injury from a discarded needle in the community. In general, PEP is not recommended following these exposures as it is usually not possible to determine: (i) whether the needle has been used or not and for what purpose; (ii) the HIV status of the source and; (iii) the interval between the needle being used and the exposure (III, grade B). Once blood has dried, HIV 'dies' within a couple of hours. Nonetheless, viable HIV has been shown to persist in syringes and needles up to 30 days depending on temperature and the size of syringe/needle: however, there are no data on the transmissibility of this virus. In studies where only small amounts of blood are in the syringe viable HIV cannot be detected after 24 hours. ${ }^{105}$

\section{Human bites}

Requests for PEP following human bites have been reported. In general PEP is not recommended following these exposures as although the risk of transmission following a bite is unknown it is likely to be extremely small (IV, grade C). Further guidance regarding the management of human bites is available at: http://www.hpa.org.uk/web/HPAwebFile/ HPAweb_C/1194947350692.

\section{Other factors which may alter the strength of recommendation}

Where factors are present which are believed to influence the probability of HIV transmission, including the presence of concurrent STI, seroconversion in the source or circumcision status, the strength of these recommendations may be increased or decreased as appropriate.

\section{CONSIDERATIONS FOR WHICH DRUG REGIMEN TO USE FOR PEP}

The choice of drugs to be used for PEP is drawn from those used in established infection. These include the nucleoside reverse transcriptase inhibitors (NRTIs), non-nucleoside reverse transcriptase inhibitors (NNRTIs) and protease inhibitors (PIs).

In established HIV infection, combination drug therapy with at least three drugs is more effective than monotherapy or dual drug regimens. It is thus recommended, when there is considered to be a significant risk of HIV transmission following risk assessment, that a triple agent regimen be advised. Theoretical considerations to support the recommendation of three drugs include the later presentation of patients for PEPSE and giving drugs with different resistance patterns, as any resistant virus in the source may be unknown.

If there is evidence that the source patient has current or past history of treatment failure, the PEP ART should be modified in relation to the drug history and/or to resistance testing, if available. Expert advice should be sought.

Individuals who are already well informed regarding the safety, tolerability and efficacy profiles of individual antiretroviral agents may have their own individual perspective on which agents they would prefer to take. Such choices should, where possible, be respected but may be affected by the composition of 'starter packs', the possible resistance 'history' of the source, local HIV primary resistance rates, and must involve consideration of toxicity profiles in the uninfected (as outlined above).

\section{Nucleoside reverse transcriptase inhibitors}

Zidovudine (an NRTI) is the only drug to date which has been studied and for which there is evidence of reduction of risk of HIV transmission following occupational exposure. However, this agent is frequently poorly tolerated, which is likely to contribute to non-adherence/completion. Studies suggest that other NRTIs including stavudine, tenofovir and emtricitabine either given in combination with PIs or given as triple nucleoside/-tide analogue regimens, are better tolerated. ${ }^{106,107}$

The improved tolerability of Truvada (a fixed dose combination of tenofovir and emtricitabine) is a key factor for its inclusion within the recommended PEP regimen (see below) (IIb, grade B). In addition, tenofovir (TDF) and emtricitabine (FTC) have been shown to have activity as PrEP and PEP in animal models of sexual exposure and are currently being evaluated in high-risk populations as monotherapy or in combination for PrEP.

Both TDF and FTC have been shown to penetrate the genital tract and rectal tissue well in animal models, reaching peak levels within 24 hours of dosing and maintaining high levels for up to seven days, characteristics which hypothetically may be advantageous for PrEP and PEP. ${ }^{67}$ TDF and FTC have also both been shown to penetrate the human male and female genital tract well. ${ }^{85}$ Truvada has also been shown to reduce acquisition of HIV when used as PrEP in MSM. ${ }^{108}$

The routine use of abacavir is not recommended. A hypersensitivity reaction is reported in up to $8 \%$ of patients with established infection. Although the risk has not been assessed in HIV-negative individuals, it is recommended that abacavir be used in exceptional circumstances only.

\section{Non-nucleoside reverse transcriptase inhibitors}

Nevirapine has in the past been used for PEP but is now known to be associated with significant toxicity. In one study, almost $10 \%$ of individuals receiving a nevirapine-based PEP regimen experienced a grade 3 or 4 elevation in transaminases with or without a rash. ${ }^{88}$ Furthermore, two health-care workers in the USA developed fulminant hepatitis, and one required liver transplantation following a nevirapine-based PEP regimen. ${ }^{90}$ (III, grade B)

Efavirenz has a lower incidence of rash; however, it may be associated with significant central nervous system disturbance at a time when individuals may be anxious, which may make it less suitable for use for PEP. ${ }^{109}$ (IV, grade C)

Newer NNRTIs (TMC125, etravirine; TMC278, rilpivirine) may also be suitable agents for PEP regimens. Side-effects of both agents include hepatitis and rash. Stevens-Johnson syndrome has been reported with etravirine. ${ }^{110,111}$

\section{Protease inhibitors}

Although PIs act at a stage of the HIV life cycle post-integration, it is anticipated that they will still add benefit in this indication since it is likely that PEP is 'aborting' rather than prophylaxing against infection and that part of this activity will be achieved 
by rendering new virions uninfective. Indinavir and nelfinavir have both been used for PEP; however, these combinations have often been poorly tolerated. In one study 6/19 (31.6\%) of health-care workers taking an indinavir-based regimen for PEP required more than two-weeks off work. ${ }^{86}$

PIs have been associated with metabolic abnormalities, lipid abnormalities, insulin resistance and diabetes mellitus in addition to gastrointestinal side-effects. Kaletra (lopinavir/ritonavir co-formulation) is the recommended PI for inclusion with PEP regimens. Kaletra frequently causes diarrhoea and other gastrointestinal disturbances ${ }^{112}$ and patients may benefit from proactive management of side-effects by the inclusion of antidiarrhoeal and antiemetic medication. The availability of ritonavir tablets now facilitates the inclusion of other boosted PIs such as atazanavir or darunavir within starter packs, both of which may be less likely to cause diarrhoea than Kaletra. However, a recent RCT comparing the use of Kaletra versus boosted atazanavir in combination with Combivir (zidovudine/lamivudine co-formulation) for 28 days demonstrated high rates of adverse events in both arms with similar discontinuation rates. ${ }^{113}$

\section{Other drug classes}

Newer classes of drugs available for the treatment of chronic infection may have a role to play in PEP. Tolerability data in established infection and use for $\mathrm{PEP}^{114}$ may in the future support the use of raltegravir (an integrase inhibitor) or maraviroc (a CCR5 inhibitor) in PEP regimens in preference to PIs. Recent data also suggest that raltegravir and maraviroc may also penetrate the genital tract well in humans, with maraviroc also achieving very high levels in the rectal mucosa following oral administration; such characteristics may also make these agents suitable for both PrEP and PEP. ${ }^{115,116}$ However, the current cost of these agents would preclude their routine use and this should currently be restricted to those where multidrug-resistant virus is known to be present in the source or if tolerability issues arise during PEP that would otherwise result in discontinuation.

\section{RECOMMENDED COMBINATIONS FOR PEP}

The recommended combinations for PEP are shown in Table 5.

\section{Starter packs}

As with the guidelines for occupational exposure, ${ }^{1}$ it may be helpful to use a starter pack. Starter packs are pre-prepared packages including 3-5 days of antiretroviral, antiemetic and antidiarrhoeal medications. The use of starter packs allows timely provision of PEP. This PEPSE regimen can be continued or modified at initial review within five days, depending on further information about the source virus and the patient's tolerance of the medication (IV, grade C).

\section{Duration of treatment}

The optimal duration of PEP is unknown. However, animal studies $^{74}$ and a case-controlled study of health-care workers ${ }^{31}$ suggest that 28 days are required to minimize the potential
Table 5 Recommended combinations for PEP

\begin{tabular}{|c|c|}
\hline Recommended combination & $\begin{array}{l}\text { Truvada (tenofovir disoproxil fumarate } \\
245 \mathrm{mg} \text {, emtricitabine } 200 \mathrm{mg} \text { ) one } \\
\text { tablet once daily* } \\
\text { plus } \\
\text { Kaletra }^{\dagger \ddagger} \text { (lopinavir } 200 \mathrm{mg} \text {, } \\
\text { ritonavir } 50 \mathrm{mg} \text { ) two tablets twice } \\
\text { daily or four tablets once daily for } \\
28 \text { days }\end{array}$ \\
\hline $\begin{array}{l}\text { *Alternative nucleoside reverse } \\
\text { transcriptase inhibitors analogues }\end{array}$ & $\begin{array}{l}\text { Stavudine } 30 \text { or } 40 \mathrm{mg} \text { twice daily } \\
\text { (according to weight) }^{\S} \\
\text { OR } \\
\text { Zidovudine } 250 \mathrm{mg} \text { twice daily** } \\
\text { plus } \\
\text { Emtricitabine } 200 \mathrm{mg} \text { once daily } \\
\text { OR } \\
\text { Lamivudine } 300 \mathrm{mg} \text { once daily** }\end{array}$ \\
\hline${ }^{\dagger}$ Alternative protease inhibitors & $\begin{array}{l}\text { Atazanavir } 300 \mathrm{mg} \text { once daily plus } \\
\text { ritonavir } 100 \mathrm{mg} \text { once daily } \\
\text { OR } \\
\text { Darunavir } 800 \mathrm{mg} \text { once daily plus } \\
\text { ritonavir } 100 \mathrm{mg} \text { once daily }\end{array}$ \\
\hline $\begin{array}{l}{ }^{\mp} \text { Alternative to protease inhibitors } \\
\text { e.g. in cases with significant } \\
\text { drug-drug interactions }\end{array}$ & $\begin{array}{l}\text { Stavudine } 30 \text { or } 40 \mathrm{mg} \text { twice daily } \\
\text { (according to weight) } \\
\text { OR } \\
\text { Zidovudine } 250 \mathrm{mg} \text { twice daily } \\
\text { OR } \\
\text { Raltegravir } 400 \mathrm{mg} \text { twice daily }\end{array}$ \\
\hline
\end{tabular}

*Truvada is the preferred agent due to pharmacokinetic considerations, tolerability and the evidence base of efficacy based on animal models for the components, i.e. tenofovir and emtricitabine

$\S$ Weight $>60 \mathrm{~kg}=40 \mathrm{mg}$ stavudine; $<60 \mathrm{~kg}=30 \mathrm{mg}$ stavudine

**Zidovudine plus lamivudine is available as Combivir; one tablet twice daily

for HIV transmission. It is recommended therefore that four weeks of PEP should be utilized in the sexual exposure setting (unless source-testing after initiation of PEPSE determines that the 'source' is HIV-negative) (III, grade B).

\section{Side-effects}

Any of the antiretroviral drugs may have side-effects and appear to be less well tolerated in HIV-negative patients receiving PEP than in HIV-positive individuals starting treatment. Many of these can be managed symptomatically, for example the use of antinausea and antidiarrhoeal medication when taking PIs. Although proximal renal tubular dysfunction and Fanconi's syndrome are well reported in patients receiving long-term Truvada therapy, this has not yet been reported in the setting of PEP but monitoring is still required. ${ }^{116}$ In individuals reporting significant intolerance to one or more PEP agents an alternative agent(s) should be selected from Table 5 (IV, grade C).

\section{ENSURING APPROPRIATE USE OF PEPSE: SERVICE PROVISION}

Given that, for optimal efficacy, PEPSE should be commenced as soon as possible after exposure ${ }^{1}$ (III, grade B), 24-hour access should be available. As with PEP following occupational exposure, it is recommended that local policies and pathways be established to enable this within a geographical network.

It is therefore likely that emergency medicine departments (or other urgent care providers) will be expected to assume significant responsibility for provision of PEPSE, with the need for support and training from areas of local expertise. Such areas 
are likely to be departments of genitourinary (GU) medicine/ sexual health, HIV medicine, infectious diseases or virology/ microbiology. The training issues are essentially those outlined comprehensively in the DH/EAGA guidance on HIV PEP. ${ }^{1}$

It is recommended that individuals presenting for PEPSE should be referred and seen as early as possible by a clinician or team experienced in the management of ART and with expertise in HIV testing and transmission - whether or not PEPSE is offered or accepted. PEPSE should not be withheld until such expertise is available. In situations where early referral to an experienced team is not feasible, access to advice from an experienced HIV clinician or team is essential. It is recommended that local policies should include 24-hour access to advice from an experienced HIV clinician, particularly for cases where the PEPSE regimen may need to be adjusted to reflect possible drug resistance in the 'source' (IV, grade C).

\section{ENSURING APPROPRIATE USE OF PEPSE: AWARENESS}

It is important that individuals potentially at risk for acquiring HIV are aware of PEP. There is evidence that levels of awareness of PEP are low among individuals with HIV as well as among $\mathrm{MSM}^{118,119}$ and that publicity campaigns can increase awareness among at risk groups. ${ }^{120}$ A study undertaken in a community cohort of HIV-negative MSM in Australia showed that despite there being high levels of awareness PEP was sought only for a minority of high-risk exposures. ${ }^{96}$ Seeking PEP following some exposures and not others appears to be related to whether the episode was 'unusual' or a 'one off' and influenced by factors such as characteristics of the sexual partner(s), the venue where the exposure took place and the use of alcohol and/or recreational drugs. ${ }^{74}$ SARCs should ensure that clients and police officers are aware of PEP, and the need for a risk assessment of HIV transmission in each case.

It is recommended that information regarding PEPSE should be proactively provided to individuals diagnosed with HIV infection, particularly if in a serodiscordant relationship (IV, grade C). Furthermore, uninfected individuals with potential for future exposure to HIV should be provided with information regarding PEPSE in addition to full discussion of other proven risk-reduction strategies. This should include information regarding the indications for PEP and that the time to initiation of PEP is crucial to ensure appropriate uptake. It is recognized that community based organizations will have a large part to play in providing this information. Consideration should be given to provision of 24-hour helpline access to enable individuals to establish whether presentation to hospital services for PEPSE is appropriate (IV, grade C).

\section{ASSESSMENT AND INITIAL MANAGEMENT OF THE INDIVIDUAL PRESENTING FOR PEPSE}

It is essential that an appropriate risk assessment be performed to enable provision of PEPSE according to the recommendations outlined above.

At presentation, and prior to administration of PEPSE, the following issues must be discussed with the individual:

- The rationale for PEPSE;

- The lack of conclusive data for the efficacy of PEPSE;
- The potential risks and side-effects of PEPSE;

- The arrangement for early follow-up with an HIV/GU medicine clinician.

The use of a consent form is not considered essential, but documentation must demonstrate that these issues have been discussed.

It is mandatory that individuals for whom PEPSE is provided undertake an HIV test (with rapid result) prior to, or shortly, after initiating therapy (IV, grade $\mathrm{C}$ ). This recommendation reflects the possibility of undiagnosed HIV infection, which would significantly alter the risk-benefit balance of shortcourse ART. It may be possible for service providers to obtain results more rapidly by considering newer technologies, such as point-of-care tests (POCTs), although caution must be given to both the higher possibility of false-positive results and the possibility of false-negative results during early seroconversion. If a POCT is reactive, this should be confirmed with a fourth generation serological test as soon as possible and PEP should not be deferred for a significant length of time. Testing should follow the conventional norms of informed consent. $^{121}$ (IV, grade C)

Those presenting for PEPSE must be seen in a GU medicine/ sexual health/HIV department at the earliest opportunity. Where this is not feasible expert advice should be sought. It is recommended that the individual be referred to a health adviser (or appropriately experienced health-care worker) where the following issues can be addressed:

- Pre-test discussion (if HIV status is as yet unknown);

- The need to continue with a further four-week course of PEPSE if the baseline result is negative;

- The need to have a follow-up HIV test 12 weeks postcompletion of PEP;

- The side-effects of the drugs and the support available in the clinic and in the community to help adherence;

- The need to utilize generic social support over the following four months;

- The need for safer sex for the following four months;

- Issues around disclosure;

- Coping strategies;

- For patients concerned about sexual risk-taking health advisers can offer ongoing risk reduction work or referral to psychology if appropriate.

It has been shown that individuals presenting for PEPSE are at higher risk of future acquisition of HIV, although it is unlikely that this was acquired during the presenting episode, ${ }^{96}$ and therefore PEPSE presenters should be encouraged to attend for future regular sexual health check-ups and consideration of onward referral for risk-reduction services (IV, grade C).

\section{FOLLOW-UP ARRANGEMENTS FOR INDIVIDUALS PRESENTING FOR PEPSE}

Regular medical follow-up is necessary for individuals receiving PEPSE to monitor tolerability and possible toxicity of the medications. Close follow-up and encouragement has been shown to improve adherence and completion of PEP. ${ }^{87,122}$ Laboratory monitoring (see Table 6) is recommended at baseline and part-way through the PEP regimen and some clinicians also undertake this at completion of PEP. Although uncommon 
Table 6 Monitoring

\begin{tabular}{|c|c|c|c|}
\hline & Baseline & 3 to 28 days & $\begin{array}{l}12 \text { weeks after } \\
\text { completion }\end{array}$ \\
\hline HIV & $\checkmark$ & & $\begin{array}{l}\checkmark \text { (4th } \\
\text { generation } \\
\text { laboratory } \\
\text { HIV Ab/Ag } \\
\text { test) }\end{array}$ \\
\hline Hepatitis A IgG & $\begin{array}{l}\text { MSM without } \\
\text { history of } \\
\text { vaccination }\end{array}$ & & \\
\hline $\begin{array}{l}\text { Hepatitis B } \\
\text { HBcore Ab } \pm \mathrm{HBsAg} \\
\text { OR } \\
\text { HBsAb and HBsAg (in } \\
\text { those people with a } \\
\text { history of hepatitis B } \\
\text { vaccination) }\end{array}$ & $\checkmark$ & & $\checkmark$ \\
\hline Hepatitis C IgG & $\checkmark$ & $\begin{array}{l}\text { HCV RNA at } \\
\text { 28-42 days in } \\
\text { those with } \\
\text { known HCV } \\
\text { exposure }\end{array}$ & $\begin{array}{l}\checkmark \text { HCV RNA in } \\
\text { those with } \\
\text { known HCV } \\
\text { exposure }\end{array}$ \\
\hline Syphilis & $\checkmark$ & & $\checkmark$ \\
\hline STI screen & If symptoms & $\checkmark$ & $\checkmark$ \\
\hline FBC & If appropriate & If appropriate & \\
\hline Renal profile & $\checkmark$ & $\checkmark$ & \\
\hline Liver profile & $\checkmark$ & $\checkmark$ & \\
\hline Glucose & $\checkmark$ & $\checkmark$ & \\
\hline Lipids & $\checkmark$ & $\checkmark$ & \\
\hline $\begin{array}{l}\text { Urinalysis or urine } \\
\text { protein:creatinine } \\
\text { ratio }\end{array}$ & $\checkmark$ & $\checkmark$ & \\
\hline Pregnancy test & $\checkmark$ & As appropriate & As appropriate \\
\hline
\end{tabular}

with current PEP combinations, if any laboratory abnormalities are identified these should be monitored until they resolve and modification of the PEP regimen may be required. ${ }^{123}$ (IV, grade C)

It is recommended that all individuals presenting for PEPSE be comprehensively screened for other STIs at an appropriate time point, in accordance with the guidelines on screening for STIs (accessible at www.bashh.org). It is essential that hepatitis B vaccination (and immunoglobulin) be considered in addition to PEP in accordance with existing guidance. ${ }^{124}$ Additionally, the opportunity should be taken for appropriate risk-reduction discussion with individuals presenting for PEPSE (IV, grade C).

It is recommended that all individuals who receive PEPSE (and those who decline but have had significant risk of exposure to HIV) be re-tested for HIV antibody/antigen at 12 weeks postexposure or post-completion of PEP if taken (IV, grade C).

\section{SPECIAL SCENARIOS}

\section{Pregnancy}

Pregnancy is not a contraindication for PEP. Expert advice should be sought.

\section{Skin rash/flu-like symptoms during or after PEP}

Individuals experiencing a skin rash or flu-like illness while or after taking PEP should be advised to attend for urgent review to exclude an HIV seroconversion illness (IV, grade C).

\section{Discontinuation of PEP prior to day $\mathbf{2 8}$}

Individuals missing doses of PEP should be counselled according to the number of missed doses and the time elapsed from the last administered dose. Persistence of PEP drugs at therapeutic levels will depend on the pharmacokinetic properties of the individual agents used in the PEP regimen. ${ }^{125}$ The half-life of Kaletra (and other PIs) is relatively short such that levels of this agent will be subtherapeutic 24 hours after a missed dose and largely undetectable by 48 hours. In contrast, both tenofovir and emtricitabine (co-formulated as Truvada) are agents with significantly longer intracellular half-lives and have been shown to persist at therapeutic concentrations in tissue for at least 72 hours after dosing. The implications for the effectiveness of PEP are unknown (III, grade B).

Owing to the complex pharmacology of these agents and their differential persistence in tissues, ${ }^{126}$ recommendations on whether and when to discontinue PEP after missed doses is largely empirical, based on biological and pharmacological rationales as well as expert opinion (IV, grade C) (see Table 7).

If discontinuation of PEP less than 72 hours since the last missed dose is related to intolerance of one or more ART agents, re-start PEP with an alternative agent(s) (see Table 5).

\section{Further high-risk sexual exposures while on PEP}

Individuals reporting further high-risk sexual exposures while receiving PEP do not need to extend the course of PEP beyond the initial 28 days. Tenofovir and emtricitabine have been shown to prevent acquisition of infection when used as PrEP in animal models ${ }^{127}$ and to reduce acquisition among $\mathrm{MSM}^{108}$ (IV, grade C).

\section{Management of individuals who repeatedly present for PEPSE or with ongoing high-risk behaviour}

There is a theoretical concern regarding repeat users of PEPSE. However, once again, there are few data suggesting that a significant number of individuals will utilize PEPSE repeatedly, 87,96 perhaps due to the aversive nature of the medications. It is therefore recommended that individuals be

Table 7 Guidance on missed doses and intolerance of PEP agents (IV, grade C)

\begin{tabular}{|c|c|c|}
\hline Scenario & Recommendation & Comments \\
\hline \multicolumn{3}{|l|}{ Missed doses } \\
\hline $\begin{array}{l}<24 \text { hours } \\
\text { elapsed since } \\
\text { missed dose }\end{array}$ & $\begin{array}{l}\text { Take missed dose } \\
\text { immediately and } \\
\text { subsequent doses at usual } \\
\text { time }\end{array}$ & $\begin{array}{l}\text { Reinforce the importance } \\
\text { of adherence and } \\
\text { re-evaluate the } \\
\text { motivation to continue } \\
\text { PEP }\end{array}$ \\
\hline $\begin{array}{l}\text { 24-72 hours } \\
\text { elapsed since } \\
\text { missed dose }\end{array}$ & Re-start PEP & $\begin{array}{l}\text { Reinforce the importance } \\
\text { of adherence } \\
\text { Re-evaluate motivation } \\
\text { of recipient to continue } \\
\text { PEP }\end{array}$ \\
\hline $\begin{array}{l}>72 \text { hours } \\
\text { elapsed since } \\
\text { missed dose }\end{array}$ & $\begin{array}{l}\text { Recommend discontinuation } \\
\text { of PEP }\end{array}$ & \\
\hline
\end{tabular}


considered for repeat courses of PEPSE according to the risk of HIV acquisition at the time of presentation, particularly if their circumstances suggest this to be appropriate (commercial sex workers, serodiscordant couples, inability to control the preventive behaviour of their partners). However, it is also recommended that repeat attenders be strongly encouraged to discuss these issues with a health adviser and/or psychologist (IV, grade C).

Individuals who present more than once a year for PEPSE, who do not otherwise have prevailing circumstances for doing so, are of greater concern. PEPSE should still be considered and provided on the basis of the advice set out in Table 4 of these guidelines but it should be made clear that in such cases the provision of PEPSE is fully integrated into a course of advice and counselling around safer sex strategies (IV, grade C). It is recommended that in light of the NICE (2007) recommendations (http://guidance.nice.org.uk/PH3), these individuals are offered one-to-one structured discussions around a model of behaviour change theory which can address factors that can help reduce risk-taking and improve selfefficacy and motivation.

\section{COST-EFFECTIVENESS OF PEP AFTER NON-OCCUPATIONAL EXPOSURE TO HIV}

There are no conclusive data regarding the cost-effectiveness of PEPSE. It has been argued that the cost of providing PEP may be effectively spent on other prevention initiatives. ${ }^{128}$ However, while the drug cost of a full 28-day course of PEP is approximately $£ 677.50$ (BNF price October 2010), the lifetime costs of treatment for an HIV-positive individual are estimated to be between $£ 280,000$ and $£ 360,000$. $^{129}$ A retrospective cost analysis of the San Francisco PEPSE programme has shown it to be costeffective when used in high-risk exposures and potentially costsaving when used after receptive anal intercourse in MSM. ${ }^{130}$ Subsequent modelling utilizing data from many USA cities ${ }^{131}$ and Australia ${ }^{132}$ suggests similar levels of cost-effectiveness provided that PEPSE is targeted to high-risk exposures consistent with those recommended within these guidelines. This is in general accordance with the recent review by the Health Technology Assessment. ${ }^{73}$

\section{SURVEILLANCE OF THE USE OF PEPSE}

From January 2011 all episodes of PEPSE should be notified centrally via the GUMCAD system. It is anticipated that a prospective monitoring scheme will be developed in conjunction with the HPA.

Any adverse events attributed to antiretroviral medications should be reported via the HIV Adverse Drug Reactions Reporting Scheme.

\section{Qualifying statement}

The recommendations in this guideline may not be appropriate for use in all clinical situations. Decisions to follow these recommendations must be based on the professional judgement of the clinician and consideration of individual patient circumstances and wishes. It should be acknowledged that use of any antiretroviral agent in this setting is an unlicensed indication.
All possible care has been undertaken to ensure the publication of the correct dosage and route of administration. However, it remains the responsibility of the prescribing physician to ensure the accuracy and appropriateness of the medication they prescribe.

\section{Applicability}

The provision of PEPSE requires consideration of appropriate pathways of care between GU medicine/sexual health/HIV clinicians and those providing access to emergency and primary care, including SARCs, in order to ensure PEPSE is administered both appropriately and in a timely fashion. This will require local interpretation of this guideline and will most likely involve a degree of organizational change and provision of additional resources.

\section{Auditable outcome measures}

- Proportion of PEPSE patients having a baseline HIV test: aim $100 \%$ within 72 hours of presenting for PEPSE;

- Proportion of PEPSE prescriptions that fit within recommended indications: aim 90\%;

- Proportion of PEPSE prescriptions administered within 72 hours of risk exposure: aim $90 \%$;

- Proportion of individuals completing 4-week course of PEPSE: aim 75\%;

- Proportion of individuals seeking PEPSE undergoing testing for STIs: aim 90\%;

- Proportion of individuals completing 12-week post-PEP HIV antibody/antigen test: aim $60 \%$.

\section{REFERENCES}

References available online only at: http:/ / www.ijsa.rsmjournals. com/cgi/content/full/22/12/695/DC1.

(Accepted 17 October 2011)

\section{APPENDIX A}

\section{POTENTIAL FOR DRUG-DRUG INTERACTIONS}

When prescribing PEP it is essential to ensure that the potential for drug-drug interactions is considered. Clinicians are advised to liaise with an HIV specialist pharmacist and/or use online tools such as http://www.hiv-druginteractions.org/ for this purpose. ${ }^{117}$ Examples of relevant drug-drug interactions between PIs and other medications are shown in Appendix A. In the majority of cases this can be managed by close observation, but may require alteration of either the co-prescribed medication or the PEP regimen as indicated. Alternative antiretroviral drugs to include in the PEP regimen in the event of significant drug-drug interactions or intolerance are shown in Table 5 (IV, grade C).

Of particular note is the interaction of ritonavir with some statins, resulting in the elevation of those statins (in particular simvastatin or lovastatin) to dangerously high levels, leading to an increased risk of rhabdomyolysis. In this case switching to an alternative statin for a short while, e.g. atorvastatin (area under the curve [AUC] also increased 5-fold) or 
pravastatin, stopping the statin for the duration of PEP, or using an alternative third (non-PI) agent may be necessary (IV, grade C).

There is some controversy regarding the dosing of emergency hormonal contraception (i.e. levonorgestrel [Levonelle $\left.{ }^{\circledR}\right]$ ) if required at the start of PEP. Some clinicians would recommend giving a double-dose since ritonavir induces the metabolism of progesterone and an increased dose of levonorgestrel does not appear to increase toxicity. Other clinicians consider this unnecessary since the induction effect is not anticipated to occur until 10-14 days after commencement of therapy. If a patient is receiving medroxyprogesterone acetate injections (Depo-Provera ${ }^{\circledR}$ ) no additional management is required (III, grade $\mathrm{B}$ ).

Consideration should also be given to the use of over-thecounter and recreational drugs. In particular the use of St John's Wort should be avoided as this may reduce the level of PIs. Individuals should be advised that ecstasy, gamma-hydroxybutyrate (GHB) and methamphetamine should be avoided as their levels may be significantly increased by ritonavir (III, grade B).

\section{DRUG-DRUG INTERACTIONS WITH KALETRA (LOPINAVIR AND RITONAVIR)}

The table below outlines the potential drug-drug interactions with Kaletra and commonly used medication, or where interactions are significant and potentially dangerous. The shaded areas are where an alternative ARV other than a boosted protease inhibitors (PI) is recommended (either another nucleoside analogue, raltegravir or consider the use of two nucleoside analogues only). Please note many of these drug-drug interactions are similar for other boosted PIs. Please seek advice from a specialist HIV pharmacist and/or use on line tools such as http://www.hiv-druginteractions.org/.

\begin{tabular}{|c|c|c|}
\hline Drug & Problem & Alternative \\
\hline \multicolumn{3}{|l|}{ Lipid-lowering agents: } \\
\hline $\begin{array}{l}\text { Simvastatin }\left(\text { Zocor }^{\mathrm{TM}}\right) \\
\quad \text { Lovastatin }\end{array}$ & $\begin{array}{l}\text { Contraindicated therefore stop at once. Large increase } \\
\text { in simvastatin or lovastatin levels - greatly increased } \\
\text { risk of myopathy including rhabdomyolysis }\end{array}$ & $\begin{array}{l}\text { Consider stopping statin for duration of PEP or } \\
\text { prescribe alternative (see below) }\end{array}$ \\
\hline Atorvastatin & Levels of atorvastatin and rosuvastatin increased & Use lowest possible dose of these statins and \\
\hline Rosuvastatin & (2-5-fold increase in AUC) & monitor for toxicity. \\
\hline Pravastatin & No interaction therefore safe to continue/prescribe & \\
\hline \multicolumn{3}{|l|}{ Fluvastatin } \\
\hline Inhaled/intranasal corticosteroids: & & \\
\hline $\begin{array}{l}\text { Fluticasone (Flixotide, Seretide }{ }^{\circledR} \text {, } \text { Flixonase }^{\circledR} \text {, } \\
\text { sofan }^{\circledR} \text {, Avamys }{ }^{\circledR} \text { ) } \\
\text { Budesonide (Rhinocort Aqua }{ }^{\circledR} \text {, Pulmicort }{ }^{\circledR} \text {, } \\
\text { Symbicort }{ }^{\circledR} \text { ) } \\
\text { Mometasone (Nasonex }{ }^{\circledR}, \text { Asmanex }^{\circledR} \text { ) }\end{array}$ & $\begin{array}{l}\text { High systemic absorption of corticosteroid. Advise } \\
\text { patient to stop using if possible (i.e. only if no risk of } \\
\text { severe asthma) }\end{array}$ & $\begin{array}{l}\text { Alternative steroid: Beclomethasone (e.g. Becotide }{ }^{\circledR} \\
\text { inhalers, Beconase }{ }^{\circledR} \text { nasal spray). Please note } \\
\text { compound preparations e.g. (Seretide }{ }^{\circledR} \text {, } \\
\text { Symbicort }{ }^{\circledR} \text { ) also include bronchodilators } \\
\text { (salmeterol, formoterol). The bronchodilators will } \\
\text { need to be prescribed separately to the steroid } \\
\text { inhalers. }\end{array}$ \\
\hline
\end{tabular}

Recreational drugs:

Ecstasy (MDMA), gamma-hydroxybutyrate (GHB), methamphetamine (and possibly other recreational drugs)

\section{Erectile dysfunction:}

Phosphodiesterase inhibitors: sildenafil, tadalafil, vardenafil
Levels of ecstasy, gamma-hydroxybutyrate (GHB) and methamphetamine may be significantly increased by ritonavir
Individuals should be advised to avoid recreational drugs for duration of PEP course
Significant increase in drug levels and effect/ side-effects of erectile dysfunction agents
Avoid co-administration where possible. If given use with caution at low doses, do not exceed maximum doses (see below) and increase monitoring for adverse events

Maximum doses: sildenafil $25 \mathrm{mg}$ every 48 hours, tadalafil $10 \mathrm{mg}$ every 72 hours, vardenafil $2.5 \mathrm{mg}$ every 72 hours (NB advice regarding safer sex while on PEP)
Potential for decrease in methadone levels. Methadone levels may be affected $7-10$ days after starting Kaletra.

Counsel patient; monitor and increase dose only if patient complains of withdrawal symptoms. On completion of PEP, methadone dose may need to be reviewed, especially if any dose adjustments have been made. Discuss with substance misuse service

Oral contraceptives and contraceptive Effectiveness may be reduced
implant

Counsel patient to use barrier method of contraception (e.g. condom) as well while on PEP and for 4 weeks after with no pill break (NB also risk of transmission)

Prednisolone, dexamethasone Levels likely to be increased

In long-term use decrease dose of steroid while on PEP (consider reducing dose of prednisolone by approx $30 \%)$ 


\section{Continued}

\begin{tabular}{|c|c|c|}
\hline Drug & Problem & Alternative \\
\hline $\begin{array}{l}\text { Diazepam, midazolam, zolpidem, } \\
\text { zopiclone }\end{array}$ & Levels of hypnotic/anxiolytic likely to be increased & $\begin{array}{l}\text { Warn patient regarding potential interaction: avoid } \\
\text { concomitant use or decrease dose. In particular, } \\
\text { caution with midazolam for day case procedures } \\
\text { in case of prolonged sedation }\end{array}$ \\
\hline Erythromycin, clarithromycin & $\begin{array}{l}\text { Potential for increase in levels of these agents - may } \\
\text { prolong QT interval. Advise patient to stop if short } \\
\text { course or reduce dose if possible }\end{array}$ & $\begin{array}{l}\text { Consider switch to azithromycin to finish antibiotic } \\
\text { course if appropriate }\end{array}$ \\
\hline \multicolumn{3}{|l|}{ Calcium channel blockers: } \\
\hline $\begin{array}{l}\text { Diltiazem, verapamil, nifedipine, felodipine, } \\
\text { nicardipine }\end{array}$ & Increased levels - increased risk of heart block & $\begin{array}{l}\text { Consider using alternative third PEP drug* } \\
\text { Alternatively liaise with GP/cardiologist regarding } \\
\text { dose adjustment }\end{array}$ \\
\hline Amiodarone and other antiarrhythmics & $\begin{array}{l}\text { Contraindicated - likely to get increase in levels of } \\
\text { antiarrhythmic drug - risk of serious and/or life } \\
\text { threatening reactions such as cardiac arrhythmias }\end{array}$ & $\begin{array}{l}\text { Do not issue Kaletra - prescribe. Truvada }{ }^{\circledR} \text { plus } \\
\text { alternative drug. }{ }^{*} \text { Discuss with cardiologist }\end{array}$ \\
\hline Digoxin & $\begin{array}{l}\text { Initial acute increase in digoxin levels - could lead to } \\
\text { toxicity }\end{array}$ & $\begin{array}{l}\text { Do not issue Kaletra - prescribe. Truvada }{ }^{\circledR} \text { plus } \\
\text { alternative drug* }\end{array}$ \\
\hline Oseltamivir (Tamiflu ${ }^{\mathbb{R}}$ ) & Possible increased CNS side-effects & Prescribe/continue at same dose - counsel patient \\
\hline \multicolumn{3}{|l|}{ Antipsychotics/neuroleptics: } \\
\hline Pimozide, clozapine & $\begin{array}{l}\text { Increase in levels and potential for life threatening } \\
\text { arrhythmias. Increase in levels may result in serious } \\
\text { haematological abnormalities }\end{array}$ & $\begin{array}{l}\text { Don't issue Kaletra - prescribe Truvada }{ }^{\circledR} \text { plus } \\
\text { alternative drug* }\end{array}$ \\
\hline $\begin{array}{l}\text { Quetiapine, haloperidol, risperidone, } \\
\text { thioridazine }\end{array}$ & Pls may increase the drug levels of these agents & $\begin{array}{l}\text { Dose reduction may be required (liaise with GP or } \\
\text { psychiatrist) or use alternative third PEP drug* }\end{array}$ \\
\hline \multicolumn{3}{|l|}{ Anticonvulsants: } \\
\hline $\begin{array}{l}\text { Phenytoin, phenobarbitone, } \\
\text { carbamazepine }\end{array}$ & $\begin{array}{l}\text { Enzyme inducers - will reduce Kaletra levels. Induction } \\
\text { effect will persist for approx } 2 \text { weeks after cessation }\end{array}$ & $\begin{array}{l}\text { Do not issue Kaletra - prescribe. Truvada }{ }^{\circledR} \text { plus } \\
\text { alternative drug }\end{array}$ \\
\hline Lamotrigine & $\begin{array}{l}\text { May require dose increase. Other anticonvulsants } \\
\text { probably safe }\end{array}$ & \\
\hline $\begin{array}{l}\text { Antidepressants (especially SSRIs and } \\
\text { related antidepressants, mirtazapine, } \\
\text { trazodone): }\end{array}$ & May get increase in drug levels of antidepressants & $\begin{array}{l}\text { Consider dose reduction and monitor for toxicity. } \\
\text { Alternatively use an alternative third PEP drug* } \\
\text { (especially with high doses of antidepressants) }\end{array}$ \\
\hline St John's Wort & $\begin{array}{l}\text { Enzyme inducer therefore will reduce Kaletra levels. } \\
\text { Induction effect will persist for approx } 2 \text { weeks after } \\
\text { cessation }\end{array}$ & $\begin{array}{l}\text { Do not issue Kaletra - prescribe. Truvada }{ }^{\circledR} \text { plus } \\
\text { alternative drug* }\end{array}$ \\
\hline Rifampicin & $\begin{array}{l}\text { Enzyme inducer - will reduce Kaletra levels. Induction } \\
\text { effect will persist for approx } 2 \text { weeks after cessation; } \\
\text { co-administration causes hepatotoxicity }\end{array}$ & $\begin{array}{l}\text { Do not issue Kaletra - prescribe. Truvada }{ }^{\circledR} \text { plus } \\
\text { alternative drug }\end{array}$ \\
\hline \multirow[t]{2}{*}{ Rifabutin } & $\begin{array}{l}\text { Will get increase in rifabutin levels and may require dose } \\
\text { reduction }\end{array}$ & $\begin{array}{l}\text { Do not issue Kaletra - prescribe. Truvada }{ }^{\circledR} \text { plus } \\
\text { alternative drug* }\end{array}$ \\
\hline & & $\begin{array}{l}\text { OR consider reduction in rifabutin dose (e.g. to } \\
150 \mathrm{mg} 3 \times / \text { week) for duration of PEP }\end{array}$ \\
\hline Warfarin & $\begin{array}{l}\text { Levels (and therefore INR) can be increased or } \\
\text { decreased }\end{array}$ & $\begin{array}{l}\text { According to indication for warfarin - monitor INR } \\
\text { closely or prescribe. Truvada }{ }^{\circledR} \text { plus alternative } \\
\text { drug* }\end{array}$ \\
\hline $\begin{array}{l}\text { Immunosuppressants (ciclosporin, } \\
\text { tacrolimus, sirolimus) }\end{array}$ & $\begin{array}{l}\text { Significant interaction to increase levels of } \\
\text { immunosuppressants }\end{array}$ & $\begin{array}{l}\text { Do not issue Kaletra - prescribe. Truvada }{ }^{\circledR} \text { plus } \\
\text { alternative drug* }\end{array}$ \\
\hline
\end{tabular}

All drug/dose changes must be made on an individual patient basis. Consider current dose when choosing dose of alternative drug

${ }^{*}$ Alternative drug to be nucleoside analogue (e.g. zidovudine $250 \mathrm{mg}$ twice daily, stavudine 30 or 40 mg twice daily according to weight) or integrase inhibitor (raltegravir $400 \mathrm{mg}$ twice daily)

${ }^{\dagger}$ Alternative drug to be nucleoside analogue only (do not use raltegravir as this may also interact) 


\section{APPENDIX B}

\section{LEVELS AND GRADING OF EVIDENCE}

\section{Table A Level of evidence}

\begin{tabular}{ll}
\hline la & Evidence obtained from meta-anlaysis of randomized controlled trials \\
Ib & Evidence obtained from at least one randomized controlled trial \\
Ila & Evidence obtained from at least one well-designed controlled study without randomization \\
Ilb & Evidence obtained from at least one type of well-designed quasi-experimental study \\
III & Evidence obtained from well-designed, non-experimental descriptive studies, such as comparative studies, correlation studies and case control studies \\
IV & Evidence obtained from expert committee reports or opinions and/or clinical experience of respected authorities
\end{tabular}

Table B Grading of recommendation

\begin{tabular}{|c|c|}
\hline $\begin{array}{l}\text { A Evidence levels la, } \\
\text { lb }\end{array}$ & $\begin{array}{l}\text { Requires at least one randomized controlled trial as part of the body of literature of overall good quality and consistency addressing the } \\
\text { specific recommendation }\end{array}$ \\
\hline $\begin{array}{l}\text { B Evidence levels Ila, } \\
\text { Ilb, III }\end{array}$ & Requires availability of well-conducted clinical studies, but no randomized clinical trials on the topic of recommendation \\
\hline C Evidence level IV & $\begin{array}{l}\text { Requires evidence from expert committee reports or opinions and/or clinical experience of respected authorities. Indicates absence of } \\
\text { directly applicable studies of good quality }\end{array}$ \\
\hline
\end{tabular}

